\title{
Commentary: First survive the crash: When to bail on the unbalanced atrioventricular valve
}

\author{
James M. Hammel, MD
}

\author{
From the Department of Cardiothoracic Surgery, Children's Hospital and Medical Center of Omaha, Omaha, Neb. \\ Disclosures: Author has nothing to disclose with regard to commercial support. \\ Received for publication Oct 5, 2018; accepted for publication Oct 5, 2018; available ahead of print Nov 20, 2018. \\ Address for reprints: James M. Hammel, MD, Department of Cardiothoracic Surgery, Children's Hospital and \\ Medical Center, 8200 Dodge, Omaha, NE 68114 (E-mail: jhammel@chsomaha.org). \\ J Thorac Cardiovasc Surg 2019;157:e299-300 \\ $0022-5223 / \$ 36.00$ \\ Copyright $(2018$ by The American Association for Thoracic Surgery \\ https://doi.org/10.1016/j.jtcvs.2018.10.017
}

Although repair of regurgitant atrioventricular valves remains preferable to replacement and is possible in the majority of cases, in some patients, satisfactory valve function cannot be achieved. The atrioventricular valve in the context of unbalanced atrioventricular septal defect is particularly commonly regurgitant, and is difficult to repair with acceptable results. ${ }^{1,2}$ A prolonged attempt at repair during cardioplegic myocardial ischemia in alreadydysfunctional myocardium risks worsening the postoperative course. Luo and colleagues ${ }^{3}$ describe the off-label application of the Melody (Medtronic, Minneapolis, Minn) transcatheter pulmonary valve in the common atrioventricular position in the management of such a patient. ${ }^{3}$

The techniques described by Luo and colleagues ${ }^{3}$ to implant the Melody valve largely mimic those described by Emani and colleagues. ${ }^{4}$ The limitations of this technique are that the location of the circumferential skirt - and therefore the distance of projection of the prosthesis into the ventricle or atrium-must either be set before examining the site of implantation or the skirt must be attached during ischemic time. Furthermore, during attachment of the skirt, a surgeon may find that the extraordinary thinness of the graft sinuses results in a frustrating tendency to inadvertently catch the very thin valve leaflet. ${ }^{4}$ If parts of the tubular portion of the prosthesis are cut away to reduce potential obstruction of an adjacent ventricular outflow tract, the factory-sutured ends of the graft are disrupted and must be resecured. An alternative technique for Melody atrioventricular valve implantation, which does not require timeconsuming preparation of the prosthesis, reduces time under cardioplegia and allows control of implantation depth and rotation as the prosthesis is deployed, has been described elsewhere.

All options for infant atrioventricular valve replacement are in some way unsatisfactory. Both mechanical and bioprosthetic heart valves have been implanted in functionally single-ventricle hearts. ${ }^{6}$ Well-known complications include thrombosis and heart block, but additional difficulties are particular to the population of patients with unbalanced atrioventricular septal defect. For example, remnant

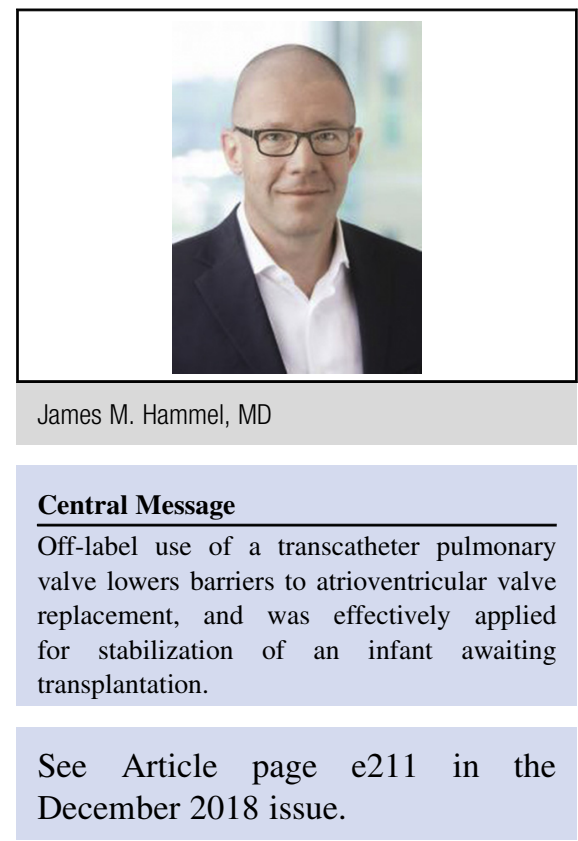

interventricular septal crest may interfere with mechanical leaflet motion or tissue valve projection, but be unsafe to resect for fear of conduction system injury. Or, the often very large common atrioventricular valve orifice may tempt a surgeon to implant a larger-than-necessary valve, but this may lead to less-vigorous movement both mechnical and adult bioprosthetic mitral valves, predisposing to stasis and thrombus deposition. The Melody valve, the tissue component of which is identical to the Contegra (Medtronic) bovine jugular venous valve graft with which surgeons may already be familiar, has certain characteristics that may make it particularly suitable for the application described by Luo and colleagues. ${ }^{3}$ The Melody valve tissue sinuses and leaflets are thin to the point of transparency and very pliable, improving valve performance index (the ratio of effective orifice area to geometric area). Plus, the functional anatomy of the venous valve allows the valve to be competent at a range of deployed diameters. Data regarding the durability of the Melody valve at systemic pressure are gradually becoming available, and its performance has been reassuring in the short term.

Although the implantation described here sacrifices the potential for natural valve growth, and may or may not allow for future dilation, this was not a concern in the case described. One of my cardiac surgeon mentors, Wayne E. Richenbacher, often said, "You have to walk away from the plane crash first before you worry about making your 
connection." Luo and colleagues ${ }^{3}$ demonstrate this principle. The Melody valve was well applied to temporize the patient in this case to improve the likelihood of survival to transplantation. This is an important tool for the armamentarium of congenital heart surgeons.

\section{References}

1. Buratto E, Ye XT, Brizard CP, Brink J, d'Udekem Y, Konstantinov IE. Successful atrioventricular valve repair improves long-term outcomes in children with unbalanced atrioventricular septal defect. J Thorac Cardiovasc Surg. 2017; 154:2019-27.
2. Honjo O, Atlin CR, Mertens L, Al-Radi OO, Redington AN, Caldarone CA, et al. Atrioventricular valve repair in patients with functional single-ventricle physiology: impact of ventricular and valve function and morphology on survival and reintervention. J Thorac Cardiovasc Surg. 2011;142:326-35.e2.

3. Luo S, Van Arsdell GS, Honjo O. Systemic atrioventricular valve replacement with a Melody valve in an infant with a single-ventricle physiology. J Thorac Cardiovasc Surg. 2018;156:e211-3.

4. Emani SM, Piekarski BL, Zurakowski D, Baird CA, Marshall AC, Lock JE, et al Concept of an expandable cardiac valve for surgical implantation in infants and children. J Thorac Cardiovasc Surg. 2016;152:1514-23.

5. Melody mitral valve implantation: rapid, simplified technique. Available at: https://www.youtube.com/watch?v=Du7oWuhHqIg. Accessed October 20, 2018.

6. Mahle WT, Gaynor JW, Spray TL. Atrioventricular valve replacement in patients with a single ventricle. Ann Thorac Surg. 2001;72:182-6. 